Book Power in Communication, Sociology and Technology

Ed. Angela Repanovici, Manolis Koukourakis, Tereza Khecyoyan

Series: Philosophy, Communication, Media Sciences

Available online at http://trivent-publishing.eu/

\title{
The Usefulness of Social Networks for the Dissemination of Scientific Information
}

\author{
Ionel Şerban \\ Transilvania University of Brasov (DPMM Department) \\ Romania, ionel.serban@unitbv.ro
}

\begin{abstract}
Nowadays there are state of the art social networks which unite people, their hobbies and concerns on global level. Knowing the impact of these social networks on everyday lifestyle, the need of such social networks may be translated in the research field. Considering the evolution of digital books and information, there is a need of fast dissemination in order for the information to be acknowledged and cited. For example, ResearchGate is a well-known social network, on global level, which offers the possibility to communicate, cite, and detect books and information regarding every aspect of research field.
\end{abstract}

Keywords: Social networks; research gate; academic; researcher; RG score 


\title{
The Usefulness of Social Networks for the Dissemination of Scientific Information
}

\author{
Ionel Şerban \\ Transilvania University of Brasov (DPMM Department) \\ Romania
}

\section{Introduction}

The rise of social networking is obvious in the last years. Not so long ago, it used to be enough to be present on the Internet for the one-way broadcasting and dissemination of information. Today, social networks such as Facebook and Twitter are creating new forms of social interaction, dialogue, exchange and collaboration. Social-media enables users to swap ideas, post updates and comments, or to participate in activities and events, while sharing their wider interests. ${ }^{1}$ The negative impact of social networking is also obvious. This chapter will highlight the positive impact that social networking has on the dissemination of information, research and books, in a century where the speed of innovation is rapidly increasing. The expectations, in terms of research, publications, and books are increasingly higher in close relation to maintaining the laws of copyright. There is the concern that the amount of information available on social-media might break copyright laws.

\section{Academic research social networking}

ResearchGate is a free social network for researchers from any scientific field. ${ }^{2}$ This provides access to applications like web.2.0, search for semantics of articles, file-sharing, and a public file server. Moreover, there is the possibility to use forums, methodological discussions, groups or create your own blog within the network, etc. ResearchGate is built by scientists, for scientists. It started when two researchers discovered first-hand that collaborating with a friend or colleague on the other side of the world was no easy task. Founded in 2008 by physicians Dr. Ijad Madisch and Dr. Sören Hofmayer, and computer scientist Horst Fickenscher, ResearchGate today has more than $13+$ million members. We strive to help them make progress happen faster. ${ }^{3}$

An exclusive feature of the network is the semantic search engine, not only in internal resources, but also in bibliographic databases such as PubMed, CiteSeer, arXiv, NASA Library, etc. Specific to this search engine is the ability to perform searches within the published works.

The platform proposes similar methods to facilitate members' connection. By analysing user information in its profile, it will suggest groups, members with similar interfaces or possible literature of interest. It also allows the job selection by field of activity or state.

\footnotetext{
${ }^{1}$ The rise of social networking. Changing the web as we know it (2010), http://www.itu.int/net/itunews/issues/2010/06/35.aspx (accessed October 10, 2017).

2 https:// ro.wikipedia.org/wiki/Researchgate (accessed October 10, 2017).

3 https://www.researchgate.net/about (accessed October 10, 2017).
} 
Using this social network researchers have the opportunity to download free of charge previously published documents, without breaking copyright laws. ${ }^{4}$ It helps to ease communication, forcing users to publish general notes as well as short scientific articles. ${ }^{5}$ Important are also Information Literacy skills to select and fins the scientific information. ${ }^{6}$ Also, researchers have to know open access sources, like institutional repositories. ${ }^{7}$

Considering, also the great impact of old book digitized, which was hard to get access to, today, social networking might be a good gateway for old manuscripts dissemination, which aren't given the right attention due to the fact that they aren't online on the internet.

From the internet we can find 5 reasons why everybody should join ResearchGate. ${ }^{8}$ These are: the access to papers, getting advice from researchers, send your work, make contacts and find jobs.

This social network also gives a RG score which has the purpose, also not yet declared, to differentiate the researchers according to some criteria. Several studies on the RG score, concluded that details about the calculation method are not published, and also the RG score was "not transparent and irreproducible". ${ }^{9}$ The incorporation of the journal impact factor into the RG score, was criticized and suggested that it should "not be considered in the evaluation of academics." The results confirmed in a second "response" study, which also found the score to depend mostly on journal impact factors. The RG score was found to be negatively correlated with network centrality, i.e., that users that are the most active (and thus central to the network) on ResearchGate usually do not have high RG scores. It was also found strongly positively correlated with Quacquarelli Symonds university rankings at the institutional level, but only weakly with Elsevier SciVal rankings of each authors. While it was found to be correlated with different university rankings, the correlation in between these rankings themselves was higher. ${ }^{10}$

\footnotetext{
4 https://www.antropologi.info/blog/anthropology/2009/selv-archiving-repositories-is-researchgatethe-solution (accessed October 10, 2017).

${ }^{5}$ See: O. Florea, I.C. Roşca, "Stokes' second problem for a micropolar fluid with slip" Plos One 10(7), (2015): published online; C. Drugă, I. Roşca, A. Repanovici, R. Necula, "Design and construction of an experimental stand for total hip and knee prosthetics testing" E-Health and Bioengineering Conference, Sinaia, Romania, (2017): 398- 401; D. Cotoros, C. Drugă, A. Stanciu, "Statistical analysis of forces developed by fingers" E-Health and Bioengineering Conference, Sinaia, Romania, (2017): 21-24; B. Braun, M. Baritz, FEM modelling of shoes insoles components for standing and walking simulation, 2017, https://www.researchgate.net/publication/312252475_FEM_

modelling_of_shoes_insoles_components_for_standing_and_walking_simulation (accessed October 10, 2017);

https://www.researchgate.net/publication/319271314_Biomaterials_Polylactic_acid_and_3D_printin g_processes_for_orthosis_and_prosthesis?_sg=Oh4WS3ZZpBfjvqa6PZ6L-

A8Q8GKCdiE3rhe_4uiE582zIoxqvAc67KFSDQOO4LKN5R1JuMuGdFamqTj0 (accessed

November 2, 2017).

${ }^{6}$ A. Repanovici, I. Barbu, L. Cristea, "Information literacy learning model for engineering students" in the $5^{\text {th }}$ LASME/WSEAS International Conference on Engineering, (2008): 73- 78.

7 A. Repanovici, "Marketing Research about Attitudes, Difficulties and Interest of Academic Community about Institutional Repository" in the Proceedings of the $3^{\text {rd }}$ International Conference on Management, Marketing and Finances, (2009): 88-95.

85 Reasons Why You Should Join ResearchGate, http://toptipbio.com/why-you-should-join-researchgate (accessed October 10, 2017).

9 P. Kraker, E. Lex, A critical look at the ResearchGate score as a measure of scientific reputation, 2015,https://www.researchgate.net/publication/277393116_A_Critical_Look_at_the_ResearchGate_ Score_as_a_Measure_of_Scientific_Reputation (accessed October 10, 2017).

10 https://en.wikipedia.org/wiki/ResearchGate (accessed October 10, 2017).
} 
Along with ResearchGate we can find other academic social networks, such as: Academia.edu, Google Scholar, Google Academic, Mendeley, Zotero, but which do not have the same popularity as the first one. All these social networks offer informal education.

Recent studies have concluded that considering the multiple profiles, that a researcher has, it is time consuming to manage all of them so it is recommended to strategically select the social network that meet their goal although it is very difficult and there is little information that might help you choose. ${ }^{11}$

American Physiological Association recommends a management guide of the online presence of every person. This guide can show that ResearchGate provides community interaction features that help distinguish it from other platforms. Their users can: ask academic questions and respond to questions; follow other researchers and receive notifications of their work; ask authors to upload full versions of their papers using the "request full text button;" request feedback on their work; create project logs, used to update work more easily and for a specific research project.

Before using these services, researchers should check the archiving policies of each journal before choosing to upload or share papers so that they do not violate the copyright policies. ${ }^{12}$

Some researchers say that if the public content of the social networking isn't filtered it may cause universities or companies to think twice before hiring a person on the job market. ${ }^{13}$

\section{Discussion and Conclusions}

In conclusion this type of social networking might be successful in disseminating information worldwide but considering reaction of some researcher's coalitions, due to copyright infringement, the access to some papers might be forbidden. Even though there will still present interest due to the possibilities to interact on research areas of interest.

All the information, papers, books transferred over the internet should carefully be taken into consideration so that there should not be any copyright infringement. Although this is very difficult and in many cases only depends on the users trust and good behaviour.

In a world where internet connectivity is the one of the main activity this types of research social networking might offer the possibility to detect, discuss, interact and lead to improvement in many areas of interest.

Considering all the recent studies it is a good start to find which of the many social networks fits you best considering your goals and time limitation for managing your profile.

\section{References}

Braun, B. and M. Baritz. FEM modelling of shoes insoles components for standing and walking simulation, 2017.

\footnotetext{
${ }^{11}$ K. Fatima, E. Carlos, Academic Social Networking Sites: A Comparative Analysis of Their Services and Tools, 2015, https://www.ideals.illinois.edu/bitstream/handle /2142/73715/380_ready.pdf.

12 http://www.apa.org/science/about/psa/2017/02/academic-social-networking.aspx (accessed October 10, 2017).

${ }^{13}$ See articles: V.R. Brown, E.D. Vaughn, "The writing on the (Facebook) wall: The use of social networking sites in hiring decisions" Journal of Business and Psychology, 26(2), (2011): 219-225; W.P. Smith, D.L. Kidder, "You've been tagged! (Then again, maybe not): Employers and Facebook" Business Horizons, 53(5), (2010): 491-499.
} 
https://www.researchgate.net/publication/312252475_FEM_

modelling_of_shoes_insoles_components_for_standing_and_walking_simulation (accessed October 10, 2017).

Brown, V.R. and E.D. Vaughn. "The writing on the (Facebook) wall: The use of social networking sites in hiring decisions." Journal of Business and Psychology, 26(2), (2011): 219-225.

Cotoros, D. and C. Drugă, A. Stanciu. "Statistical analysis of forces developed by fingers." E-Health and Bioengineering Conference, Sinaia, Romania, (2017): 21-24.

Drugă, C. and I. Roşca, A. Repanovici, R. Necula. "Design and construction of an experimental stand for total hip and knee prosthetics testing." E-Health and Bioengineering Conference, Sinaia, Romania, (2017): 398- 401.

Fatima, K. and E. Carlos. Academic Social Networking Sites: A Comparative Analysis of Their Services and Tools, 2015. https://www.ideals.illinois.edu/bitstream/handle /2142/73715/380_ready.pdf.

Florea, O. and I.C. Roşca. "Stokes' second problem for a micropolar fluid with slip." Plos One 10(7), (2015): published online.

Kraker, P. and E. Lex. A critical look at the ResearchGate score as a measure of scientific reputation, 2015.https://www.researchgate.net/publication/277393116_A_Critical_Look_at_the_ ResearchGate_Score_as_a_Measure_of_Scientific_Reputation (accessed October 10, 2017).

Repanovici, A. and I. Barbu, L. Cristea. "Information literacy learning model for engineering students." In $5^{\text {th }} L A S M E / W S E A S$ International Conference on Engineering, (2008): 73- 78.

Repanovici A. "Marketing Research about Attitudes, Difficulties and Interest of Academic Community about Institutional Repository." In the Proceedings of the 3rd International Conference on Management, Marketing and Finances, (2009): 88-95.

Smith, W.P. and D.L. Kidder. "You've been tagged! (Then again, maybe not): Employers and Facebook." Business Horizons, 53(5), (2010): 491-499.

\section{Internet sources:}

The rise of social networking. Changing the web as we know it, 2010.

http://www.itu.int/net/itunews/issues/2010/06/35.aspx (accessed October 10, 2017).

5 Reasons Why You Should Join ResearchGate. http://toptipbio.com/why-you-should-joinresearchgate (accessed October 10, 2017).

https://ro.wikipedia.org/wiki/Researchgate (accessed October 10, 2017).

https://www.researchgate.net/about (accessed October 10, 2017).

https://www.antropologi.info/blog/anthropology/2009/selv-archiving-repositories-is-

researchgate-the-solution (accessed October 10, 2017).

https://www.researchgate.net/publication/319271314_Biomaterials_Polylactic_acid_and_3

D_printing_processes_for_orthosis_and_prosthesis?_sg=Oh4WS3ZpBfjvqa6PZ6L-

A8Q8GKCdiE3rhe_4uiE582zIoxqvAc67KFSDQOO4LKN5R1JuMuGdFamqTj0

(accessed November 2, 2017).

https://en.wikipedia.org/wiki/ResearchGate (accessed October 10, 2017).

http://www.apa.org/science/about/psa/2017/02/academic-social-networking.aspx (accessed October 10, 2017). 